\title{
A ADAPTAÇÃO DA CRÔNICA COMO TRANSFERÊNCIA DE SENTIDOS*
}

\author{
Silvânia Siebert** \\ Silvana Mabel Serrani***
}

Resumo: A proposta deste trabalho é pensar uma leitura da adaptação, a partir da crônica A mulher que fuma, de Mario Prata. Entendemos que esse gesto de leitura e produção possa ser pensado discursivamente, em sua beterogeneidade, a partir das noções de tradução e de transferência de sentidos. Distanciando-nos da noção de fidelidade, pensaremos a adaptação como processo e analisaremos aspectos relativos à subjetividade e à autoria, tendo o texto de imagem como discurso que particulariza essa transferência de sentidos, como uma nova materialidade significante que passa a ser lida e interpretada por um outro leitor, o que lê imagens em movimento, o teleleitor. A análise discursiva nos permite compreender as mudanças dos sentidos entre uma obra e outra, marcando a importância das condições de produção e veiculação para a interpretação das produções culturais e poetológicas pelos sujeitos.

Palavras-Chave: Adaptação. Crônica. Tradução. Subjetividade. Autoria.

\section{INTRODUÇÃO}

Neste texto, buscamos analisar como se dá a relação entre tradução e adaptação tendo como base os estudos de Lefevere (2007) e Amorim (2005). Embora considerem que ambos os processos são formas semelhantes de transposição de sentidos, apontam também diferenças, e é entre elas que buscamos espaço para a inscrição deste trabalho. Nosso interesse está em analisar discursivamente a adaptação buscando identificar como funciona o processo de ler um texto, interpretá-lo e colocá-lo em funcionamento a partir de outra materialidade significante. Para atingir os objetivos delineados, amparamo-nos nos estudos de Authier-Revuz (1999, 2004) e Orlandi

\footnotetext{
* Trabalho resultado da tese de doutorado em fase final desenvolvida no Programa de PósGraduação em Linguística Aplicada, da Unicamp, sob a orientação da Profa. Dra. Silvana Mabel Serrani.

** Professora do Curso de Comunicação Social da Unisul. Doutoranda do Curso de Pós-graduação em Linguística Aplicada da Unicamp. Email: silvania@cinemaistv.com.br

*** Professora Titular do Programa de Pós-Graduação em Linguística Aplicada da Unicamp. Email: serrani@iel.unicamp.br
} 
(2001a, 2001b, 2004), tendo como corpus' a crônica de Mario Prata $A$ mulher que fuma, publicada no jornal O Estado de São Paulo (2002) e então "adaptada" para o meio audiovisual (2004), e também publicada na antologia do autor (PRATA, 2007, p.79, 80). Entendemos este gesto interpretativo, realizado na mesma língua, como transferência de sentidos. Para tanto, analisaremos as condições enunciativas entre o texto-fonte e o adaptado, buscando compreender o movimento dos sentidos entre um texto e outro, tendo em vista termos como encenação e texto de imagem, que iremos analisar na última seção deste artigo.

\section{A TRADUÇÃO E A ADAPTAÇÃO}

As condições de produção e distribuição de bens e artefatos culturais na pós-modernidade nos apresentam um número considerável de enunciados, textos e discursos que são recontados, retratados, redesenhados, reescritos, ou seja, apresentam-se como "re"criações de obras ou textos que, em muitos casos, reconhecemos como traduções e/ou adaptações. É por meio do gesto interpretativo de tradutores e adaptadores que muitos leitores na atualidade têm acesso a textos que foram compostos em outras línguas ou em outras épocas. Trata-se de um gesto de reescritura que vem ganhando atenção dos pesquisadores, por envolver questões que vão além das discussões sobre fidelidade (entre um texto e outro), e alcançam os domínios das produções estéticas e históricas.

Para Lefevere, estudioso da tradução de textos literários, a tarefa do tradutor é tomada como uma forma "mais reconhecível de reescritura e a potencialmente mais influente por sua capacidade de projetar a imagem de um autor e/ou de uma (série de) obra(s) em outra cultura, elevando o autor e/ou as obras para além dos limites de sua cultura de origem" (2007, p. 24-25). O autor considera ainda, além das traduções,

\footnotetext{
1 "O corpus é [...] dotado de uma forma reconhecível que poderá ser explorada. Não é a necessidade de uma forma como essa que eu quero salientar aqui, mas preferencialmente as 'maneiras de ver' que destacam as formas de corpus geralmente realizadas em AD [Análise de Discurso]: estas encontram, efetivamente, seu princípio nas tipologias, implícitas ou explícitas, colocadas a priori, em classificações espontâneas em categorias das quais se destacam os efeitos pedagógicos e políticos, ligadas à 'memória' da AD" (COURTINE, 2006, p. 21).
} 
obras reescritas - como as histórias da literatura ou compilações mais compactas -, obras de referência, antologias, críticas ou edições adaptadas para atender a correntes ideológicas ou poetológicas vigentes (LEFEVERE, 2007).

Tradução e adaptação não são, para Amorim, conceitos indistintos "mas inscritos na própria diversidade que possibilita a existência (contraditória) de diferentes concepções de textualidade e de tradução ao longo da história. Não são também conceitos independentes e livres de transbordamento em suas fronteiras" (2005, p. 230). Como ideia geral, tradutores teriam o compromisso de reproduzir um texto com fidelidade ao original, enquanto adaptadores poderiam reformular o texto, agregando ou suprimindo trechos e/ou personagens, entre outras possibilidades. Contudo, mesmo nos casos em que o adaptador recebe uma "autorização" para promover mudanças, não é possível dizer que a adaptação se distancia da relação de fidelidade entre a obra-fonte e a adaptada. Ainda são comuns julgamentos - por parte de leitores, espectadores e críticos - que estabelecem se a obra adaptada é fiel à obra original ou não. E quanto maior a semelhança entre a obra original e a adaptada mais certeiro, ou fiel, o processo de adaptação será considerado. A comparação entre obras adaptadas, uma vez baseada na noção de fidelidade, acaba dando ao leitor/telespectador a ilusão de que pouco ou nada se perdeu nesse processo. Nas palavras de Johnson (2003, p. 42),

A insistência na "fidelidade" - que deriva das expectativas que o espectador traz ao filme, baseadas na sua própria leitura do original - é falso problema porque ignora diferenças essenciais entre os dois meios, e porque geralmente ignora a dinâmica dos campos de produção cultural nos quais os dois meios estão inseridos. Enquanto um romancista tem à disposição a linguagem verbal, com toda a sua riqueza metafórica e figurativa, um cineasta lida com pelo menos cinco materiais de expressão diferentes: imagens visuais, a linguagem verbal oral (diálogo, narração e letras de música), sons não verbais (ruídos e efeitos sonoros), música e a própria língua escrita (créditos, títulos e outras escritas)

SILVA - Educação ambiental... 
Johnson destaca a particularidade da adaptação a partir de sua materialidade significante; seria impossível, segundo o autor, promover comparações de fidelidade quando tratamos de formas materiais tão diferentes. Se a relação de fidelidade textual não constitui uma questão válida, entendemos que a perspectiva discursiva nos permite analisar o texto em sua heterogeneidade, em suas diferenças. Assim, a adaptação será analisada neste texto como processo enunciativo, como uma prática de reformulação que coloca em evidência a relação do texto com seu ambiente discursivo.

Para procedermos à análise enunciativa, tomaremos a noção de heterogeneidade mostrada formulada por Authier-Revuz (1999, p. 10), como a manifestação dos diversos tipos de "negociação" do sujeito com os "outros", conceito que nos permitirá observar esse movimento do sentido da adaptação, que coloca em funcionamento um texto em outra materialidade significante. Ainda segundo Authier-Revuz (1999), as práticas de reformulação da política, da pedagogia e da publicidade produzem um discurso segundo, em função do alvo visado. A investigação da autora sobre a reformulação discursiva foi desenvolvida com base em um discurso específico, o de divulgação científica, que se constitui em um discurso reformulado da ciência para o grande público. O discurso da adaptação audiovisual, por sua vez, se constitui em um discurso reformulado de um texto-fonte - geralmente literário - para outros meios, objetivando atingir um maior número de "leitores/telespectadores/ouvintes" em outras mídias, mobilizando os textos verbais e não verbais.

Para Authier-Revuz (2004, p. 12), no discurso indireto o locutor funcionaria como uma espécie de tradutor "fazendo uso de sua próprias palavras, ele remete a um outro como fonte de 'sentido' dos propósitos que relata". A autora nos mostra a dimensão que toma a forma-sujeito tradutor para o processo enunciativo do discurso indireto, uma vez que, ao enunciar, o tradutor se colocaria como um "intermediário", que usa suas próprias palavras para dar sentido a um outro. Orlandi (2004, p.138), em sua releitura de Authier-Revuz, para investigar o discurso de divulgação científica, faz uma distinção conceitual entre os termos tradução e transferência, considerando os estudos realizados na mesma língua. Contrapondo-se a Roman Jakobson (1973), que denomina intralingual a tradução de passagens dentro da mesma língua, Orlandi 
considera que quando falamos em um mesmo idioma realizamos transferência de sentidos e não tradução.

$\mathrm{Na}$ transferência de sentido trabalha-se pois com o efeito metafórico, ou seja, há uma historicização do sentido de tal maneira que ele vai se ressignificar em um outro lugar, produzindo efeitos que trazem os sentidos que estão sendo produzidos por uma outra discursividade. (ORLANDI, 2004, p. 138)

Ao traduzir um texto, segundo a autora, o tradutor teria que mobilizar dois idiomas diferentes, o que caracterizaria primeiramente a tradução, enquanto a transferência se daria entre textos produzidos na mesma língua.

\section{ADAPTAÇÃO, TRANSFERÊNCIA E DISCURSO}

Pensamos ser necessário ressaltar que existe um distanciamento considerável entre as duas posições discursivas, pois não estamos trabalhando com línguas diferentes, mas com discursos diferentes. Por isso, neste texto adotaremos o termo transferencia, como proposto por Orlandi para os estudos da divulgação científica, marcando esta posição de analisar a adaptação, em seu movimento, a partir de um texto que é lido, interpretado e reescrito para funcionar em outro meio, em outro modo de produção e significação. Analisaremos a adaptação a partir da perspectiva discursiva, segundo a qual o texto/discurso possui determinações externas para sua existência e os sujeitos não são senhores dos seus dizeres. Todo discurso nasce em outros - sua matéria-prima - e se direciona para outro(s), de modo contínuo. A adaptação, assim, serve de exemplar para analisarmos o percurso do texto num continuum, porque se constitui um gênero de entremeio.

Para compreendermos discursivamente como ocorre o processo de adaptação audiovisual, recortaremos um gênero específico, a crônica, a partir do exemplar $A$ Mulher que fuma, que foi publicada no jornal e 
"adaptada" para o audiovisual ${ }^{2}$. Nesse processo discursivo, o sujeito que adapta a crônica está ressignificando a obra na mesma língua, mas em um outro momento da história. É um gesto de interpretação que mantém uma regularidade e ao mesmo tempo provoca deslocamentos. A versão adaptada para o audiovisual tem o texto-fonte (TF), a crônica, como parte das condições de produção, mas o olhar lançado pela adaptadora sobre a obra-fonte relacionando-a ao seu contexto de enunciação e ao sujeito telespectador serão determinantes para a criação dessa nova versão. Assim, a análise da constituição, da formulação e da circulação da crônica audiovisual é determinante para compreendermos o processo discursivo da adaptação.

Entendemos que, ao mudar a materialidade do texto, como em nosso exemplar, a crônica $A$ mulher que fuma, que passa a funcionar no meio audiovisual, não reproduz o movimento de colocar a funcionar o mesmo texto em uma mídia diferente. $O$ trabalho resultante desse processo de transferência é o texto audiovisual adaptado, fruto da imbricação textual/discursiva da obra-fonte com os textos verbais e o não verbais resultantes do gesto de interpretação da adaptadora sobre a constituição, a formulação e a circulação da crônica. Nesse processo, o texto de imagem constitui um elemento que particulariza essa transferência discursiva.

o texto de imagens também tem na sua constituição marcas de heterogeneidade, como o implícito, o silêncio, a ironia. Marcas, porém, que não podem ser pensadas como vozes, porque analisar o não-verbal pelas categorias do verbal implicaria na redução de um e outro. Nesse caso, por associação ao conceito de polifonia, formulamos o conceito de policromia (SOUZA, 1995). Buscando analisar a imagem com mais pertinência.

O conceito de policromia recobre o jogo de imagens e cores, no caso, elementos constitutivos da linguagem não-verbal, permitindo, assim, caminhar na análise do discurso do não-verbal. $\mathrm{O}$ jogo de formas, cores, imagens, luz, sombra, etc. nos remete, à semelhança das vozes no texto, a diferentes perspectivas instauradas pelo eu na e pela imagem, o que favorece não só a

\footnotetext{
2 A mulher que fuma em audiovisual está disponível em: $<$ http://www.youtube.com/watch?v=UHV4AT9-0Ds>.
} 
percepção dos movimentos no plano do sinestésico, bem como a apreensão de diferentes sentidos no plano discursivo-ideológico, quando se tem a possibilidade de se interpretar uma imagem através de outra (SOUZA, 1998, p. 8)

Souza apela ao conceito de policromia para analisar o texto de imagem que é constitutivo das obras audiovisuais, levando em conta, para sua análise, as formas, cores, imagens, luz, sombra, etc. No movimento de adaptação da crônica $A$ mulher que fuma, a adaptadora e diretora Carol Romano lê uma obra e a interpreta para funcionar no meio audiovisual, para o texto de imagem com elemento verbal, projetando um leitor/telespectador localizado em uma cena enunciativa "em que [o sujeito] se enuncia e que ao mesmo tempo produz e é pressuposta para se legitimar" (ORLANDI, 2001a, p. 25-26). A adaptadora realiza um gesto interpretativo com triplo movimento de interpretação, pois lê em um discurso e diz em outros dois (verbal/imagem).

Nesse processo discursivo, a adaptadora ocupa uma posição similar à do jornalista de divulgação científica, pois lê em um discurso que será enunciado em outro contexto, com outros discursos -, mas também diferente, porque conta com uma materialidade significante outra: a imagem, que não é visível sem o processo de interpretação. Segundo Souza (1998, p. 5), "há imagens que não estão visíveis, porém sugeridas, implícitas a partir de um jogo de imagens previamente oferecidas. Outras são apagadas, silenciadas dando lugar a um caminho aberto à significação, à interpretação". Ler a imagem não é o mesmo que ler o texto verbal. O conceito de policromia cunhado por Souza revela o texto de imagem como uma ordem discursiva própria, com um funcionamento diferente do texto verbal, sendo a co-relação entre os elementos constitutivos da imagem fator que permite estabelecer que uma imagem se ligue a outra, constituindo um texto e, consequentemente, permitindo sua interpretação, independente do verbal. O resultado, como na divulgação científica, é de uma nova versão, o que desencadeia novos gestos de interpretação (ORLANDI, 2004). 
Ao ler e interpretar a crônica-fonte, a adaptadora relaciona a obra adaptada a posições imaginárias diferentes daquelas em que se coloca o cronista Prata. Romano trabalha com uma nova materialidade significante para ser lida e interpretada por um outro leitor, o que lê imagens em movimento, o teleleitor. Assim, para compreendermos os lugares enunciativos dos diferentes textos resultantes do processo de adaptação, recorremos à noção de encenação, conceito que contribui da mesma maneira que as determinações linguísticas para forjar as imagens que os interlocutores (adaptador e teleleitor) enviam uns aos outros numa comunicação, nas quais a cenografia garantiria a credibilidade das enunciações.

A cenografia discursiva - constituída pelo eu/tu-agora-aqui do discurso em termos de locutor, destinatário, cronografia e topografia - é compreendida pelo fato de que o que funciona no discurso são relações que se reproduzem em um mecanismo de substituições. (ORLANDI, 2001b, p. 154).

Em $A$ mulher que fuma, Romano ocupa duas posições enunciativas: é a adaptadora e a diretora da obra; seu gesto interpretativo da cenografia discursiva permitirá a escrita do texto de imagem no roteiro, com a marcação de locações, planos, figurinos, atores, fotografia, entre outros fatores que, ao serem interpretados e escritos, levam em conta as condições de realização e circulação da obra, projetados a partir da criação da cenografia discursiva, de uma encenação. Vejamos como isso acontece colocando em relação as duas obras.

$\mathrm{Na}$ crônica fonte, por exemplo, o cronista escreve sobre a sensualidade da mulher que fuma (PRATA, 2007, p.79): “A mulher que fuma é, antes mais nada, sexy". A sensualidade da mulher estaria, na delicadeza do fumar, no prazer de fumar... O que não ocorre com os homens que fumam por questões machistas, como escreve Prata (p. 79): "Sim, porque homem fumar pode ser até um ato machista. O mundo inteiro fazendo campanha contra a nicotina e o homem lá, todo macho: fumo mesmo, e dai?’. Para o cronista, as mulheres fumam porque são femininas e suaves como a fumaça. Por sua vez, a adaptadora Carol Romano não estabelece essa comparação de forma direta no texto de 
imagem e nem no texto verbal, conforme se pode observar nos recortes que seguem.

Texto de imagem - Uma mulher de peignoir (sobre um baby-doll negro), na cama, iluminada pelo abajur, acende um cigarro (Figura 1); um homem chega ao balcão de um bar, afrouxa a gravata e é servido com uma dose de whisky (Figura 2). A trilha sonora instrumental acompanha o texto de imagem.

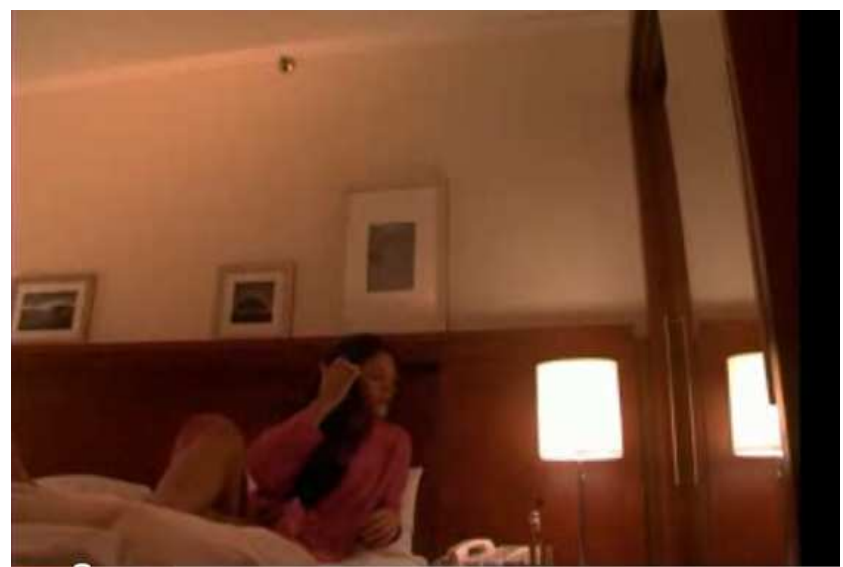

Figura 1-A mulher que fuma acende cigarro

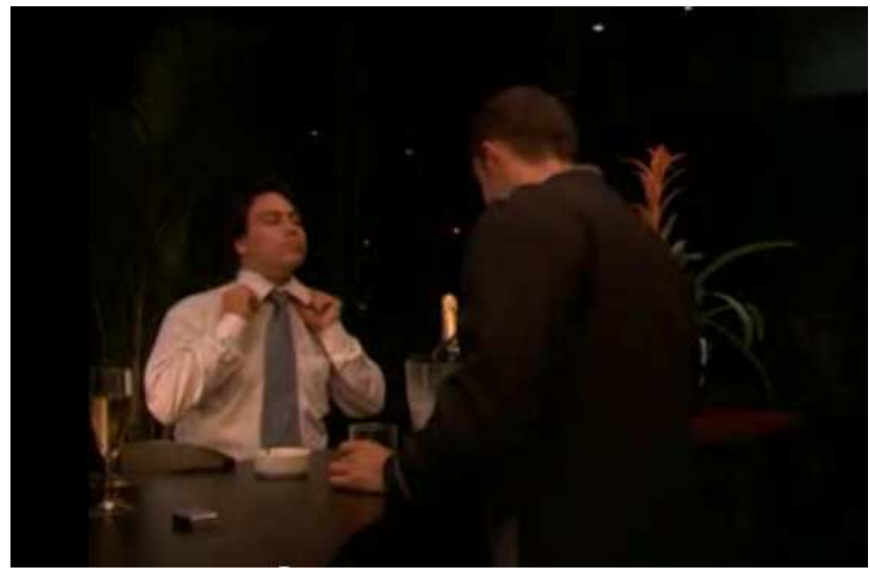

Figura 2-O homem no bar

SILVA - Educação ambiental... 
Romano cria diferentes cenografias para a protagonista. A mulher que fuma, no texto-fonte, não é descrita em um bar, ou em um quarto; Prata se concentra em descrever a ação de fumar, detalhando minuciosamente seus gestos, sua delicadeza em sorver a fumaça, em apagar o cigarro, sendo o leitor responsável pela construção de sua cena enunciativa. $\mathrm{O}$ cronista descreve o prazer em vê-la fumar. $\mathrm{Na}$ crônica audiovisual, no texto/imagem, a mulher ganha forma definida, sendo corporificada como uma morena de cabelos longos, de boca sensual, fumando em um quarto, onde também o cronista ganha forma - homem moreno, com seus trinta anos de idade, que admira a personagem a distância, ocupando dois lugares enunciativos: o de um homem que, sentado no bar, admira a mulher que fuma no bar e também a observa no quarto, e narra a história. Participa das duas cenas como voyeur e narrador. A mobilidade no tempo e no espaço ocupado pelo cronista voyeur é o resultado do movimento triplo de interpretação da adaptadora, que projeta diferentes cenografias discursivas para a nova versão. Romano reescreve os textos verbal e de imagem determinada pelas condições de produção audiovisual, em que a significação do texto é determinada pela constituição, formulação e circulação.

De acordo com a cenografia apresentada, podemos entender a supressão dos primeiros parágrafos da crônica-fonte do roteiro da adaptação como um apagamento discursivo significativo. $\mathrm{Na}$ passagem para o audiovisual há um silenciamento da figura de um homem, o machista, que é cortada da crônica audiovisual e que no texto-fonte tem uma voz importante que se contrapõe à mulher que fuma. Essa supressão marca o distanciamento entre o texto-fonte e a obra adaptada, revelando o texto como uma outra versão. A exclusão do homem machista poderia estar relacionada, entre outras coisas, aos custos de produção, já que a entrada do personagem exigiria, para sua realização, a contratação de um ator, a produção de outra locação ou locações, figurino, maquiagem, horas de trabalho da equipe, etc. Esses elementos do texto de imagem exigem como condição de produção mais tempo e dinheiro, o que acaba implicando em cortes de cenas, ou sequências nas obras adaptadas, tanto nas versões realizadas para o cinema, como para a televisão e para a internet. Todavia, essa é uma das interpretações possíveis, já que tanto a interpretação do texto verbal como do não verbal é definida por cada leitor/telespectador. 
Ao adaptar, Romano apaga o personagem machista da crônicafonte, tanto no texto verbal como no não-verbal, o que provoca uma mudança significativa entre o ponto de vista do cronista, Mario Prata, e da adaptadora, Carol Romano. Prata lança o olhar sobre a mulher que fuma e é amada, Romano perpassa o olhar do ator/cronista falando como autora, de uma mulher que fuma e é desejada. Esse gesto de interpretação marca a diferença entre um texto e outro, entre a adaptação e o texto-fonte, evidenciando a posição da adaptadora que interpreta, realiza e coloca-se como autora, e atribui outro sentido à mulher que fuma, utilizando outras cenografias.

Será somente a partir do terceiro parágrafo da crônica de Mario Prata (2007, p. 79) que a adaptadora estabelecerá relação direta com o texto-fonte, a partir da frase: "É feminina e como". Nesse ponto começa a história da crônica adaptada. Começa pela voz do cronista/personagem/ator que admira uma mulher que fuma, e diz: "feminina, muito feminina...", acompanhada pelo texto de imagem que mostra uma mulher morena, sensual, numa cama de hotel fumando.

O homem que narra, com a voz em off, está em um bar tomando uma bebida. A partir desse ponto, começamos a encontrar marcas de discurso direto entre o texto-fonte e o texto adaptado, que AuthierRevuz (2004, p. 12) define como "palavras do outro que ocupam o tempo - ou espaço - claramente recortado da citação na frase; o locutor se apresenta como simples 'porta-voz"'. Acompanhemos no exemplo que segue:

a) Crônica-fonte - Admire a tragada, que faz com que seus lábios participem de um movimento no mínimo excitante. $O$ puxar da fumaça para os pulmões faz com que seus seios se ergam magicamente um ou dois centímetros. E, para completar, ainda passa a língua descaradamente pelos lábios.

b) Crônica adaptada (texto verbal) - Queria ser fumaça para me incorporar às suas curvas. Os lábios sugam, incitam a imaginação. A distância lhe beijo os olhos. Por dentro me toca de tesão. Os seios se erguem.

c) Crônica adaptada (texto/imagem) - É madrugada; em um quarto de hotel, uma mulher, morena, bonita, fuma um cigarro na cama (Figura 3). Em outra cena, à noite, num bar, um homem 
com cerca de 30 anos toma uma bebida (Figura 4). A mulher fuma de forma sensual. Um homem no quarto de hotel observa a mulher na cama, e está com a camisa desabotoada. A mulher continua fumando vagarosamente. O homem está no bar e é servido de outra bebida. O homem no quarto de hotel observa a mulher fumando. Ela enche os pulmões de fumaça e os seios arfam. O homem no quarto de hotel afrouxa a gravata.

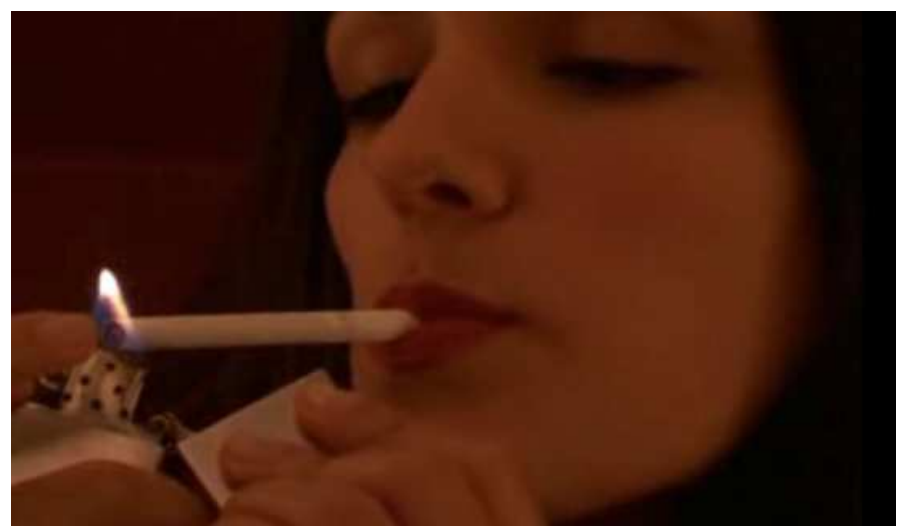

Figura 3 - A mulher começa a fumar

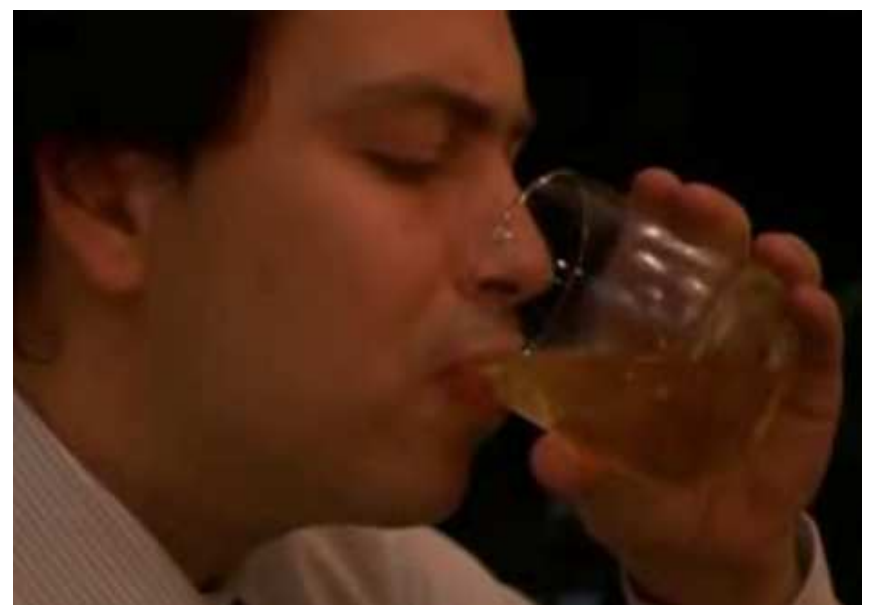

Figura 4-O homem começa a beber 
Ao analisarmos o fio discursivo dos textos acima, encontramos marcas de discurso direto - com a reescrita de frases literais do textofonte - apresentadas como marcas do discurso indireto - em que o locutor assume outras vozes remetendo a outros textos. Neste processo de transferência entre uma obra e outra teremos a paráfrase como ponto de partida, em que a verossimilhança entre o texto-fonte e a adaptação ganha destaque, e que, segundo Achard, serve para estabelecermos uma ligação com o que já passou: "a memória não restitui frases escutadas no passado, mas julgamentos de verossimilhança sobre o que é reconstituído pelas operações de paráfrase” (1999, p. 16). Há relação intertextual entre o já-dito e o dito. Os textos verbais das crônicas fonte e adaptada - funcionam segundo o movimento da verossimilhança, tendo o texto de imagem como participante ativo dessa narrativa, pois reitera a escrita. Quando isto ocorre, silencia-se a heterogeneidade do texto de imagem, criando a ilusão de ter havido uma transferência direta de uma obra à outra, e entre um significado e outro, trazendo ao leitor/telespectador a falsa ilusão de fidelidade através da paráfrase.

A cenografia discursiva no texto adaptado funcionaria tanto para mobilizar a memória do TF, quanto para criar novas aberturas para a interpretação, como ocorre no início da crônica audiovisual, em que o texto de imagem é colocado em evidência.

\section{TEMPO E ESPAÇO - DÊIXIS}

Uma marca de autoria da adaptadora aparece no texto de imagem, na montagem do trabalho, nas pausas, nos gestos dos atores, na forma de apresentar o voyeur, ao mesmo tempo em dois lugares, no quarto e no bar. A noção de espaço é outra na correlação com o texto-fonte. A articulação realizada na adaptação entre os textos verbais e não verbais propõe uma estrutura narrativa que rompe com a noção de tempo e espaço, enquanto na obra de Mario Prata (TF) a linha do tempo é linear, com começo, meio e fim, e dura o tempo de fumar um cigarro. $\mathrm{Na}$ crônica audiovisual o tempo fica suspenso, indefinido, como um efeito provocado pelo texto de imagem. 
O tempo é trabalhado a partir da montagem de ações paralelas entre os dois personagens que aparecem tanto no bar como no quarto de hotel, quebrando a linearidade dos eventos apresentados na crônica fonte. O movimento do tempo, em diferentes direções, fica evidenciado e concomitantemente provoca a abertura para a interpretação de diferentes sentidos. O cronista e a mulher se conheceriam? Seriam amantes? Se fossem, teriam se conhecido naquele bar, no dia da narrativa? As perguntas são colocadas, mas não são respondidas pela imagem. O movimento do ir e vir da montagem, envolvendo os protagonistas, nos provoca essas dúvidas no processo de interpretação. Isso é possível, segundo Souza, quando se interpreta a imagem.

Ao se interpretar a imagem pelo olhar - e não através da palavra - apreende-se a matéria significante em diferentes contextos. O resultado dessa interpretação é a produção de outras imagens (outros textos), produzidas pelo espectador a partir do caráter de incompletude inerente, eu diria, à linguagem verbal e não-verbal. O caráter de incompletude da imagem aponta, dentre outras coisas, a sua recursividade. Quando se recorta pelo olhar um dos elementos constitutivos de uma imagem produz-se outra imagem, outro texto, sucessivamente e de forma plenamente infinita (SOUZA, 1998, p. 8)

Esse aspecto da crônica audiovisual - de trabalhar com as diferentes dimensões do tempo a partir da montagem - diz respeito à incompletude do texto de imagem, o que provoca um movimento interpretativo, remetendo esse texto a outros. Esse efeito, a princípio, nos faz pensar que o texto de imagem, em função de sua montagem não linear do tempo, permite à crônica audiovisual mostrar sentidos que se constituem de forma diferente daqueles apresentados na crônica impressa. Entendemos que tais aspectos conferem à crônica audiovisual uma possibilidade outra de se realizar como discurso, trabalhando a tensão entre a paráfrase e a polissemia, revelando a criatividade envolvida no processo de transferência. 
No desfecho da crônica adaptada revela-se outra marca de criatividade no que é dito, e que fica evidenciada pela mudança de posição de leitura, entre uma obra e outra. Na crônica fonte, o cronista enuncia para um sujeito leitor que poderia ser tanto uma mulher como um homem, já na crônica adaptada é o ator voyeur que se coloca em uma relação enunciativa com o leitor/telespectador, que é homem. Essa mudança de posição enunciativa permite a mudança do sentido, de mulher amada (CF) para mulher desejada (CA). Nos textos verbal e de imagem, a cenografia também corrobora com a mudança de sentidos da enunciação, mostrando pelo texto de imagem (Figuras 5, 6, 7, 8) a ação paralela, do cronista/voyeur que está no quarto de hotel e também no bar do hotel a observar a mulher desejada. Acompanhemos nos recortes:

a) Crônica-fonte - E se você olha para o filtro, vê a marca de um batom que poderia estar - quem sabe - nos nossos lábios. E não pense que ela apaga o cigarro dando porradas nele. Não. Ela passa a bituca de um lado para o outro do cinzeiro, sem pressa, como se estivesse pincelando alguma coisa. Deviam proibir o cigarro só para os homens. Que teriam o prazer do cigarro apenas na boca da mulher amada. Pra que mais?

b) Crônica adaptada (texto verbal adaptado) - A marca de batom no filtro poderia estar no meu lábio. Ah... Anuncia o fim sem pressa, como que dando os últimos retoques. Deveriam proibir o cigarro para nós homens, que teríamos o prazer do cigarro apenas na boca da mulher desejada. Pra que mais?

c) Crônica adaptada (texto/imagem) - Homem observa a mulher no quarto (Figura 5). Mulher apaga o cigarro, bem devagar. Homem está no bar, continua bebendo e ao lado está sentada a mulher morena que fumava no quarto (Figuras 6, 8). Ele fica observando-a (Figura 7), acompanhado da trilha musical. 


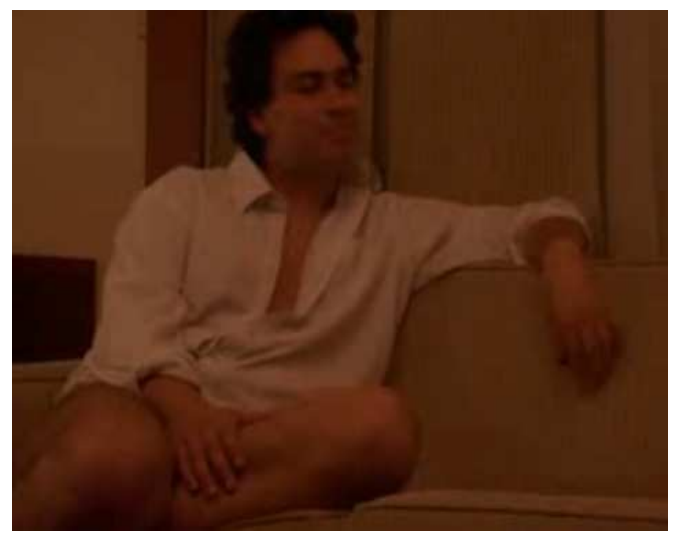

Figura 5 - O homem no quarto

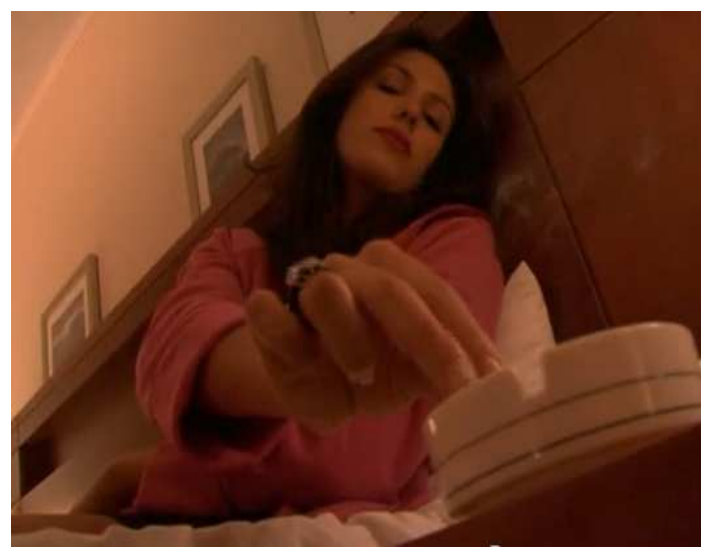

Figura 6 - A mulher apaga o cigarro 


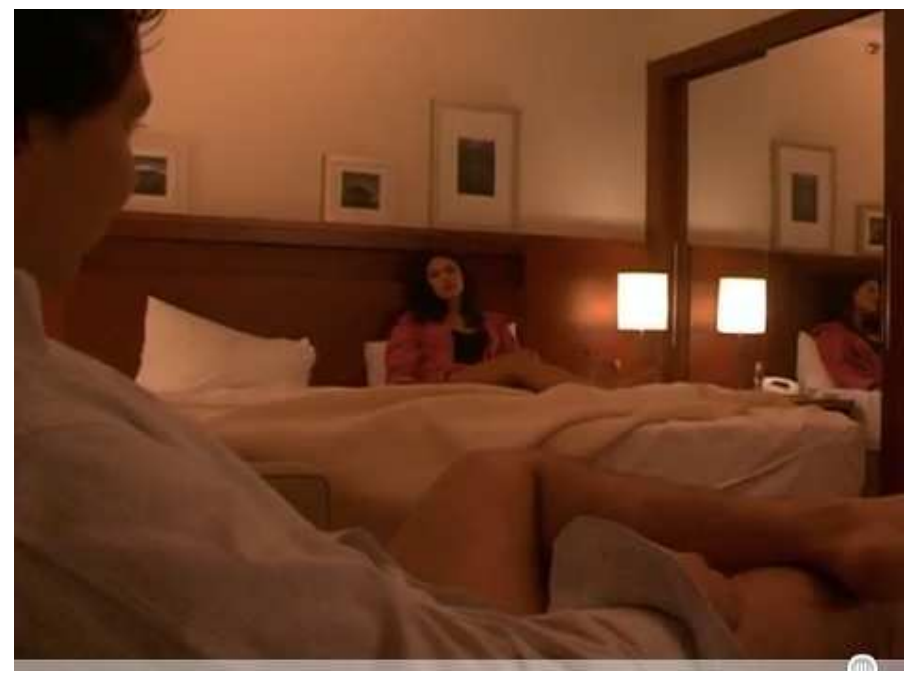

Figura 7 - O homem admira a mulher à distância.

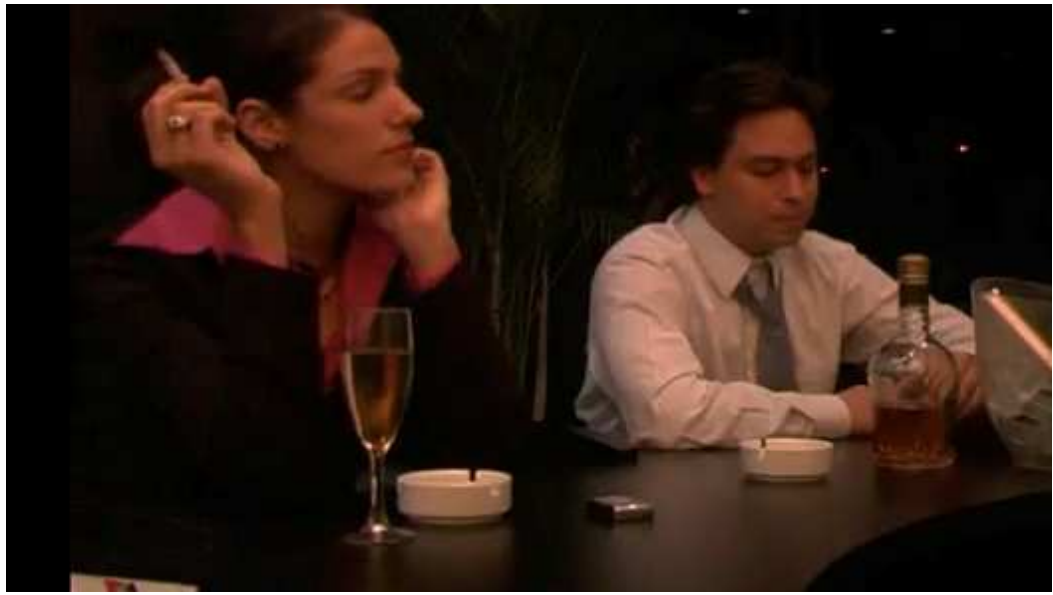

Figura 8-A mulher e o homem no bar. 
Nesta análise de transferência de sentidos da crônica $A$ mulher que fuma é possível identificar regularidades e diferenças discursivas entre uma versão e outra, evidenciando a heterogeneidade discursiva constitutiva do discurso de adaptação. Revelando o papel da adaptadora como reprodutora do texto-fonte, evidenciado na análise das paráfrases do discurso direto do texto-fonte e do texto adaptado, mas também como autora e produtora de sentidos quando da escrita e realização do texto de imagem, ao retratar outras cenografias e subverter a narrativa linear do TF, por meio da mudança na dêixis, com a realização da ação paralela entre cronista/voyeur e protagonista. Dessa forma, entendemos que o texto de imagem pode servir como textualidade que reitera o texto verbal, mas também, por sua constituição outra, permite a produção e a realização de um novo texto, de uma nova interpretação. A adaptação dá título ao processo e ao produto, no qual a criatividade do adaptador é autorizada a funcionar na medida em que mantém referências diretas ao texto-fonte.

\section{CONCLUSÃO}

Por meio da análise discursiva do exemplar analisado - $A$ mulher que fuma - foi possível observar a adaptação como um gesto de interpretação que mantém o TF funcionando, mas que promove mudanças, principalmente a partir do funcionamento do texto de imagem, que se apresenta como textualidade que amplia a possibilidade de significação no processo de adaptação. O que nos faz pensar que o processo de transferência de sentidos, na adaptação, ocorre de forma diferente daquela realizada na tradução. A adaptação se constitui em um discurso de entremeio, como o de divulgação científica, que coloca em jogo a reprodução, mas que ao mesmo tempo revela a autoria e a criatividade em seu gesto interpretativo, dando ao adaptador a dimensão de autor. Ao tomar, principalmente, o texto de imagem como um texto com funcionamento diferente ao verbal, o adaptador provoca uma possibilidade outra de ler o texto adaptado, distante da noção de tradução que tenta apagar a presença do sujeito tradutor como autor, daquele que coloca em funcionamento um texto em outra língua. 
A diferença entre as materialidades garantiria novas formas de expressividade ao texto que foi retrabalhado para o funcionamento enunciativo audiovisual, articulando outras esferas enunciativas. Uma mudança significativa que coloca em jogo sentidos, históricos, ideológicos, marcando diferentemente o gesto da leitura de traduzir e adaptar.

\section{REFERÊNCIAS}

ACHARD, P. Memória e produção discursiva do sentido. In: ACHARD, P. et alii. Papel da memória. Tradução e introdução: José Horta Nunes. Campinas: Pontes, 1999. p. 11-21.

AMORIM, L. M. Tradução e adaptação: encruzilhadas da textualidade em Alice no País das Maravilhas, de Lewis Carrol, e Kim, de Rudyard Kipling. São Paulo: Editora da UNESP, 2005.

AUTHIER-REVUZ, J. Dialogismo e divulgação científica. Rua, Revista do Núcleo de Desenvolvimento da Criatividade, n. 5, p. 9-15, 1999.

Entre a transparência e a opacidade: um estudo enunciativo do sentido. Porto Alegre: Editora da EDIPUCRS, 2004.

COURTINE, J.-J. Metamorfoses do discurso político: as derivas da fala pública. Tradução de Nilton Milanez e Carlos Piovezani Filho. São Carlos: Claraluz, 2006.

JAKOBSON, R. Lingüística e Comunicação. Tradução de Izidoro Blikstein e José Paulo Paes. São Paulo: Cultrix, 1973.

JOHNSON, R. et alii. Literatura e cinema, diálogo e recriação: o caso de Vidas Secas. In: Literatura, cinema e televisão. São Paulo: Editora Senac e Instituto Itaú Cultural, 2003. p. 38-59.

LEFEVERE, A. Tradução, reescrita e manipulação literária. Tradução de Claudia Matos Seligmann. Bauru: Editora EDUSC, 2007.

ROMANO, C. A mulher que fuma. Direção de Carol Romano; produção de Fabiana Altikes; roteiro Carol Romano; fotografia Marcello Pellegrino; música André Paschoalini. 12 ${ }^{\mathbf{a}}$ Mostra de Filmes da FAAP, 2004. Disponível em: $<$ http://www.youtube.com/watch?v=UHV4AT9-0Ds >. Acesso em: 22 jun. 2011.

ORLANDI, E. Divulgação científica e efeito leitor: uma política social urbana. In: GUIMARÃES, E. (Org.). Produção e circulação do conhecimento. V. I: Estado, mídia, sociedade. Campinas, São Paulo: Pontes, 2001a. p. 21-30. 
Discurso e texto: formulação e circulação dos sentidos. Campinas, SP: Pontes, 2001b.

Cidade dos sentidos. Campinas, SP: Pontes, 2004.

PRATA, M. A mulher que fuma. O Estado de São Paulo, 23 de janeiro de 2002.

Cem melhores crônicas (que na verdade, são 129). São Paulo:

Planeta do Brasil, 2007. p. 79-80.

SOUZA, T. C. C. Discurso e imagem: perspectivas de análise não verbal.

Ciberlegenda, Revista Eletrônica do Mestrado em Comunicação, Imagem e Informação, Niterói, n. 1, 1998.

Recebido em 10/10/11. Aprovado em 22/12/11.

Title: The adaptation of the chronicle as a transference of senses

Author: Silvânia Siebert; Silvana Mabel Serrani

Abstract: The present work is a reflection on the reading of an adaptation, using the chronicle $A$ mulher que fuma, by Mario Prata. One understands that such a gesture of reading and production may be thought of discursively, in its heterogeneity, based on the notions of translation and transference of senses. Keeping the notion of fidelity at bay, here adaptation is seen as a process while aspects relating to subjectivity and authorship are analyzed. One must consider that the image text as a discourse that particularizes such a transfer of senses, as a new signifying materiality, is read and interpreted by another reader, that who reads moving images, the telereader. Discourse analysis allows one to understand the changes of the senses from one work to the other, stressing the significance of the conditions of production and of distribution for the interpretation of cultural and poetic productions by the subjects.

Kewwords: Adaptation. Chronicle. Translation. Subjectivity. Authorship.

Título: La adaptación de la crónica como transferencia de sentidos

Autor: Silvânia Siebert; Silvana Mabel Serrani

Resumen: La propuesta de este trabajo es pensar una lectura de la adaptación, a partir de una crónica La mujer que fuma, de Mario Prata. Entendemos que ese gesto de lectura y producción pueda ser pensado discursivamente, en su heterogeneidad, a partir de las nociones de traducción y de transferencia de sentidos. Distanciándonos de la noción de fidelidad, pensaremos la adaptación como proceso y analizaremos aspectos relativos a la subjetividad y autoría. Teniendo el texto de imagen como discurso que particulariza esa transferencia de sentidos, como una nueva materialidad significante que pasa a ser leida e interpretada por otro lector, él que lee imágenes en movimiento, el telelector. El análisis discursivo nos permite comprender los cambios de los sentidos entre una obra y otra, marcando la importancia de las condiciones de producción y vehiculación para la interpretación de las producciones culturales y poetológicas por los sujetos.

Palabras-clave: Adaptación. Crónica. Traducción. Subjetividad. Autoría.

Linguagem em (Dis)curso, Tubarão, SC, v. 11, n. 3, p. 543-562, set./dez. 2011 